\title{
Novel use of combined Dual Knife and endoloop for resection of a large pedunculated colon polyp
}

A 56-year-old man underwent a screening colonoscopy, in which a pedunculated polyp, $4 \mathrm{~cm} \times 2.8 \mathrm{~cm}$ in size with a $2.5-\mathrm{cm}$ wide flat stalk, was identified in the sigmoid colon ( Fig. 1). For the safe and complete resection of the polyp, prophylactic endoclips (Hx-600-135; Olympus, Hachioji-shi, Tokyo, Japan) were applied to both sides of the stalk but appeared to be ineffective ( $\bullet$ Fig. 2 ). We then applied a detachable endoloop (MAJ-254; Olympus, Hachioji-shi, Tokyo, Japan) over the stalk ( Fig. 3). Because it was difficult to capture the stalk by going around the large head of the polyp using a conventional diathermic snare, we used the Dual Knife (KD-650 Q/U; Olympus, Hachiojishi, Tokyo, Japan) with an electrosurgical generator (Endocut 50W; Coagulation 30W; ICC 200; ERBE Co., Tübingen, Germany) to cut the stalk under direct vision $(\checkmark$ Fig. 4; $\square$ Video 1 ). After resection, the polyp was gently dragged into the rectum for spontaneous passage. Histological examination confirmed the polyp to be a tubulovillous adenoma without malignant change.

In this presentation of a pedunculated polyp with very large head, conventional diathermic snare polypectomy with enbloc resection was impossible. Piecemeal resection of very large pedunculated polyps has been reported before [1,2]; however, we did not consider this option due to the increased risk of bleeding, and the risk of an inadequate tissue sample. The Dual Knife, with either a 2-mm (KD$650 \mathrm{~L})$ or $1.5-\mathrm{mm}$ (KD-650Q/U) cutting knife, can be used for the endoscopic submucosal dissection. The knob-shaped tip of the needle knife makes the needle less likely to slip during resection of polyps. Cutting the stalk of a polyp under direct vision is a safe method irrespective of the size of the polyp head. In conclusion, we consider this technique safe and effective for the management of such polyps in cases where conventional polypectomy techniques have failed.

\section{Video 1}

Using the Dual Knife for cutting the stalk of the polyp above the level of ligation under direct vision.

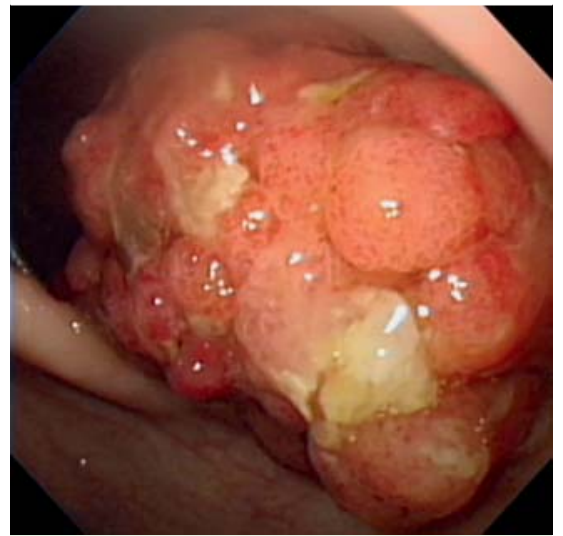

Fig. 1 A large pedunculated polyp with head $4 \mathrm{~cm} \times 2.8 \mathrm{~cm}$ in size and $2.5-\mathrm{cm}$ wide flat stalk seen in the sigmoid colon.

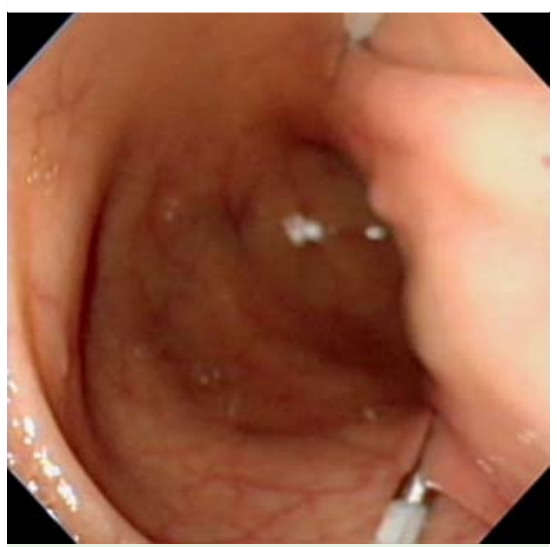

Fig. 2 Despite placement of two clips on both sides of the wide flat stalk, there was sufficient blood supply to the polyp and it showed no cyanotic change.

\section{Endoscopy_UCTN_Code_TTT_1AQ_2AD}

\section{Competing interests: None}

\section{W. Yang, H. H. Yen}

Department of Gastroenterology, Changhua Christian Hospital, Changhua, Taiwan

\section{References}

1 Binmoeller KF, Bohnacker S, Seifert $H$ et al. Endoscopic snare excision of "giant" colorectal polyps. Gastrointestinal endoscopy 1996; 43: $183-188$

2 Stergiou N, Riphaus A, Lange P et al. Endoscopic snare resection of large colonic polyps: how far can we go? International journal of colorectal disease 2003; 18: $131-135$

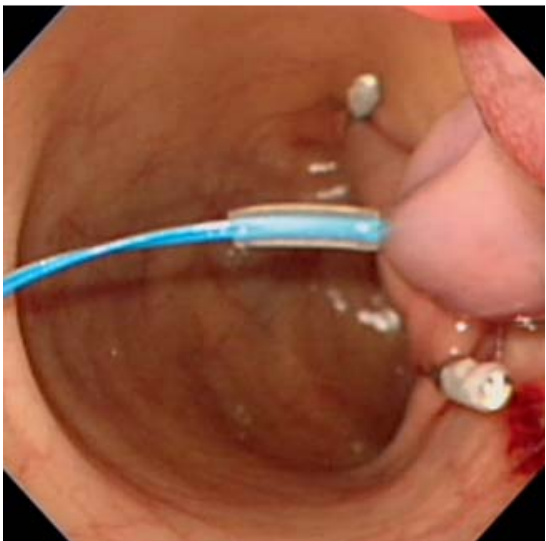

Fig. 3 After applying one detachable endoloop, the part of the polyp above the level of ligation became cyanotic and changed shape from flat to columnar, confirming sufficient tightening.

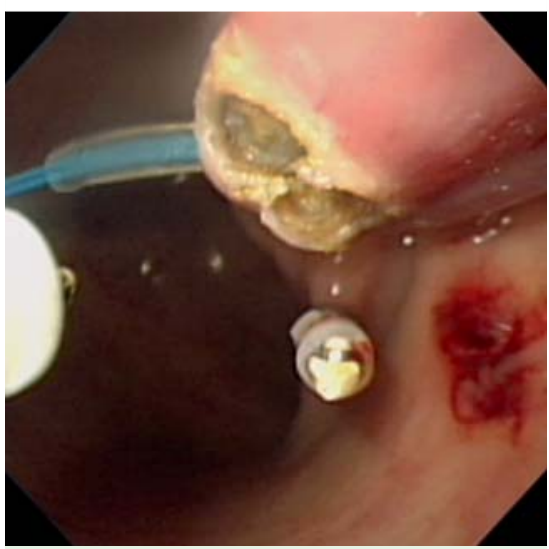

Fig. 4 Using the Dual Knife for cutting the stalk of the polyp above the level of ligation under direct vision.

Bibliography

DOI $10.1055 / \mathrm{s}-0030-1256232$

Endoscopy 2011; 43: E192

(c) Georg Thieme Verlag KG Stuttgart · New York . ISSN 0013-726X

\section{Corresponding author}

\section{W. Yang}

Department of Gastroenterology

Changhua Christian Hospital

Changhua

Taiwan

Fax: +886-7-7228289

97601@cch.org.tw 